\title{
Emergency Major Surgery in Thoracic Trauma: Timing and Decision Process
}

\author{
Eray Çınar ${ }^{1} \mathbb{D}, K_{\text {Kubilay İnan²(D), Özgür Ömer Yıldız }}^{3 \mathbb{D}}$ \\ 1 Turkish Ministry of Health, General Directorate of Emergency Medical Services, Ankara, Turkey \\ 2 Ankara City Hospital, Department of Thoracic Surgery, Ankara, Turkey \\ 3 Ankara Yıldırım Beyazıt University Faculty of Medicine, Department of Thoracic Surgery, Ankara, Turkey
}

\begin{abstract}
Background: Surgery is required in $10-15 \%$ of patients with thoracic injuries. Surgery performed within the first few hours of the injury is considered as an emergency surgery. The aim of study is to share our experiences with emergency surgical approaches in thoracic trauma.
\end{abstract}

Methods: Our study was carried out between June 2012-June 2020, by retrospective analysis of cases who were evaluated for thoracic trauma in the emergency department and who underwent emergency surgery.

Results: There were 5784 patients who requested for thoracic surgery consultation due to thoracic trauma. Of these cases, 1317 $(22.8 \%)$ were patients who were evaluated in the emergency service due to isolated thoracic trauma. There were 18 patients $(1.3 \%)$ who underwent emergency surgery for isolated thoracic trauma.

Glasgow score was higher in the group that was discharged after recovery among all groups; and this was statistically significant $(\mathrm{p}=0.045)$. It was statistically significant that intubation and low modified trauma scores were a poor prognostic factor (respectively $\mathrm{p}=0.035, \mathrm{p}=0,025)$.

Conclusions: Tube thoracostomy is sufficient for most of the thoracic traumas. After emergency evaluation, fast and correct decision in the appropriate surgical indication significantly reduces mortality.

Keywords: Thoracic Trauma, Emergency Surgery, Prognostic Factors.

\section{INTRODUCTION}

Thoracic trauma constitutes $25-50 \%$ of all traumatic injuries, and it is one of the main causes of death in all age groups in the world (1). Majority of the fatal thoracic injuries can be treated with emergency invasive interventions such as the provision of rapid ventilation through intubation, tube thoracostomy, thoracentesis and pericardiocentesis.
Thoracic trauma can be classified as blunt and penetrating thoracic trauma. Blunt thoracic trauma constitutes $70 \%$, and penetrating thoracic trauma constitutes $30 \%$ of all cases of thoracic trauma $(2,3)$. Blunt thoracic trauma is a common in the emergency departments. The most common pathologies accompanying the thoracic trauma are the fractures of the rib, sternum and clavicle, rib, 
the costal, sternum and clavicle fractures, hemothorax, pneumothorax, ruptures of the diaphragm, cardiac injury, pneumomediastinum and parenchymal injuries of the lung. The most common finding is the rib fracture (3). Emergency thoracotomy is generally performed in patients, who are evaluated in the emergency department with massive bleeding, who have hypotension, who develop cardiopulmonary arrest, and whose tube drainage continues after the tube thoracostomy. The indications of delayed surgical operation are continuous or recurrent bleeding, mediastinal widening, hemoptysis and recurrent hemothorax (1). Some patients may require exploratory thoracotomy, and surgical removal of the foreign body via thoracotomy during the course of the trauma.. Thoracic trauma of the large vessels and the heart, and thoracic traumas with massive bleeding are generally caused by the gunshot wounds. Patients, who have to be intubated due to respiratory distress after flail chest, are the patients who are performed emergency thoracotomy (4). If flail chest causes severe paradoxical breathing, it necessitates intubation and surgery. In cases of thoracic injury, 10$15 \%$ of patients require thoracotomy (5). Emergency thoracotomy refers to the thoracotomy performed within the first few hours of the injury (6).

The aim of the study is to share our experience about emergency surgical approaches in chest traumas evaluated in the emergency department and undergoing emergency surgery.

\section{MATERIALS AND METHODS}

Our study was conducted based on the retrospective examination of the cases, who were evaluated in the emergency department due to thoracic injury, and who were performed emergency surgery, between June 2012 and June 2020 in the clinics where we provide healthcare services. The information regarding age, gender, type of trauma, radiological findings, interventions in the emergency department and vital signs, Glasgow coma scores, the first thoracic surgery interventional procedure administered in the emergency department, administration of intubation in the emergency department, localization of the trauma, indication of emergency surgery, the surgical operation performed, the length of hospitalization and the results of the treatment were recorded in the database using the files of the cases included in the study. These data were analyzed in detail, and mortality analysis was performed using Revised Trauma Score (7). The Revised
Trauma Score is one of the more common scores aimed at measuring the functional consequences of an injury. It uses three specific physiologic parameters: the Glasgow Coma Scale, systemic blood pressure and the respiratory rate. Scoring in the revised trauma score ranges from 0 to 4.

As the score increases, the risk of mortality and morbidity decreases. The Revised Trauma Score, which was modified in the study by Champion et al. (7), there are three specific clinical parameters (GCS, respiratory rate and systolic blood pressure). Accordingly, each parameter is scored between 0 and 4 , and a score between 0 and 12 is obtained for each patient with trauma. It has been reported that the patients with trauma scores below 11 are associated with very high mortality rates.

\section{Ethical statement}

Ankara City Hospital Ethics Committee of the Ministry of Health Provincial Health Directorate on 25/06/2020 (No: E1-20-825)

\section{Statistical analysis}

The data obtained were evaluated using SPSS for Windows Version 23.0 software. Variables, means, standard deviations and percentages were recorded. KolmogorovSmirnov and Shapiro-Wilk normality tests were performed to test the normal distribution. In the analysis of variables without normal distribution, the means of the pairs were compared using the non-parametric Mann-Whitney U test. In order to find the direction and magnitude of the relationship between the categorical (nominal) variables, the nonparametric Spearman's rho correlation coefficient was calculated. Kendall's tau-b and Spearman's rho correlation coefficients were calculated in order to find the direction and size of the relationship between the continuous variable and the categorical variable.

Multidimensional Scaling (MDS), which is a multivariate statistical analysis, is used for analyzing behavioral data such as personal preferences, attitudes, tendencies and expectations. The representation of the objects of interest in single or multi-dimensional space is obtained through MDS analysis based on the distance values, consisting of observed similarities or differences between objects or units. This chart demonstrates how the variables change according to each other. 


\section{RESULTS}

There were 5784 patients that were referred for emergency thoracic surgery consultation due to thoracic trauma, and 18 of these patients $(0.31 \%)$ underwent emergency surgery after evaluation. All of these patients were male. The mean age was 26.8 (15-57). When the types of trauma were examined, there were $5(27.8 \%)$ sharp object injuries, 7 gunshot wounds (38.9\%), 3 assaults $(16.7 \%), 1$ traumatic asphyxia (5.6\%), 1 non-traffic accident (5.6\%), 1 in-vehicle traffic accident $(5.6 \%)$.

Of the patients, who were evaluated in the emergency department, 7 (38.9\%) patients underwent emergency surgery without radiological imaging, and 11 (61.1\%) patients underwent emergency surgery after radiological imaging. When the localizations of the trauma in the patients were evaluated, $13(72.2 \%)$ had trauma localized in the left hemithorax and $5(27.8 \%)$ had trauma localized in the right hemithorax. The mean score was found as 11.5 (4-15) in the evaluation performed in the emergency department using the Glasgow coma scale. While 11 of the patients underwent tube thoracostomy as the first intervention in the emergency department before surgery, 7 patients were performed surgery without tube thoracostomy. Of the 7 patients that did not undergo tube thoracostomy, 6 were not performed thorax CT due to their emergency. In the 1 patient with traumatic asphyxia, to whom Thorax CT was performed, there was an anamnesis due to squeezing in a construction truck dumper. Looking at the vital signs of the patients, arterial blood pressure $(\mathrm{ABP})$ examinations revealed normal BP values in 13 patients (72.2\%), and hypotension in 5 (21.8) patients. According to the laboratory data, it was observed that hemoglobin values were between 4.8 and 13.4 (mean; $9.9 \mathrm{~g} / \mathrm{dl}$ ). There were 9 patients with hemoglobin values below 10. In patients with the lowest hemoglobin values of $4.8 \mathrm{~g} / \mathrm{dl}$ and $6.8 \mathrm{~g} / \mathrm{dl}$, the lowest Glasgow coma values were found as 5 and 4 , respectively.

While 6 patients were intubated in the emergency department, 12 of them were not intubated. Thorax-CT was not performed to 4 of the patients, who were intubated. In these patients, the HGB values were between 4.8 and 12.4 $\mathrm{g} / \mathrm{dl}$, and the mean HGB value was found to be $8.2 \mathrm{~g} /$ dl. All of these cases had hypotension. Tube thoracostomy was performed in only 1 patient, whose HGB value was $12.4 \mathrm{~g} / \mathrm{dl}$, and Glasgow coma score was 10 .

When the indications of emergency surgery were examined, massive drainage was observed in 10 (55.6\%) patients $(800-1600 \mathrm{cc}$ (mean $1200 \mathrm{cc})$ ), hypovolemic shock was observed in $5(27.8 \%)$ patients, open thoracic injury was observed in $2(11.1 \%)$ patients, and cardiac arrest was observed in $1(5.6 \%)$ patient.

Among 9 patients (50\%), who were diagnosed with vascular injury due to trauma, $1(5.6 \%)$ patient had internal thoracic artery injury, 7 (38.9\%) patients had injury to the intercostal artery, and 1 patient $(5.6 \%)$ had superior pulmonary vein injury. In addition, 2 (11.1\%) patients were diagnosed with cardiac injury.

The findings of the Thorax-CT were analyzed in detail. The type and localization of the trauma, surgical indication and the surgical operation are presented in the Table 1. 
Table 1. Classification according to type of trauma, CT findings, surgical indication and surgical operation performed

\begin{tabular}{|c|c|c|c|c|}
\hline Patient & Trauma & CT Findings & Indication for surgery & Type of Surgery \\
\hline 1 & Gunshot injury & no & Cardiac arrest & $\begin{array}{l}\text { LAT + ligation of intercostal } \\
\text { artery }\end{array}$ \\
\hline 2 & Gunshot injury & no & Hypotensive shock & $\begin{array}{l}\mathrm{S}+\text { repair of left anterior cardiac } \\
\text { and superior vena cava injuries }\end{array}$ \\
\hline 3 & Asphyxia & $\begin{array}{l}\text { Total left lung } \\
\text { parenchymal bleeding }\end{array}$ & Hypotensive shock & LAT + pneumonectomy \\
\hline 4 & $\begin{array}{l}\text { Stab and impalement } \\
\text { wounds }\end{array}$ & $\begin{array}{l}\text { Massive right } \\
\text { hemothorax }\end{array}$ & continuing drainage & $\begin{array}{l}\mathrm{RT}+\text { repair of parenchyma }+ \\
\text { ligation of thoracic internal } \\
\text { artery }\end{array}$ \\
\hline 5 & $\begin{array}{l}\text { Stab and impalement } \\
\text { wounds }\end{array}$ & no & Hypotensive shock & $\mathrm{RT}+$ repair of cardiac injury \\
\hline 6 & Gunshot injury & $\begin{array}{l}\text { Left hemothorax and } \\
\text { defect of anterior chest } \\
\text { wall }\end{array}$ & continuing drainage & $\begin{array}{l}S+\text { repair of parenchyma and } \\
\text { chest wall deformity }\end{array}$ \\
\hline 7 & Gunshot injury & no & Hypotensive shock & $\mathrm{S}+\mathrm{LAT}+$ repair of cardiac injury \\
\hline 8 & Gunshot injury & no & Hypotensive shock & $S+$ repair of parenchyma \\
\hline 9 & $\begin{array}{l}\text { Stab and impalement } \\
\text { wounds }\end{array}$ & $\begin{array}{l}\text { Massive left } \\
\text { hemothorax }\end{array}$ & continuing drainage & $\mathrm{LT}+$ repair of parenchyma \\
\hline 10 & Gunshot injury & Left hemothorax & continuing drainage & $S+$ repair of parenchyma \\
\hline 11 & $\begin{array}{l}\text { Stab and impalement } \\
\text { wounds }\end{array}$ & $\begin{array}{l}\text { Left } \\
\text { hemopneumothorax }\end{array}$ & continuing drainage & $\begin{array}{l}\mathrm{LT}+\text { repair of parenchyma }+ \\
\text { ligation of intercostal artery }\end{array}$ \\
\hline 12 & Acts of violence & $\begin{array}{l}\text { Left lower lobal } \\
\text { contusion and } \\
\text { pnemothorax }\end{array}$ & continuing drainage & $\begin{array}{l}\text { LVATS + ligation of intercostal } \\
\text { artery }\end{array}$ \\
\hline 13 & Acts of violence & $\begin{array}{l}\text { Right } \\
\text { hemopneumothorax } \\
\text { and multiple costal } \\
\text { fractures }\end{array}$ & continuing drainage & $\begin{array}{l}\text { RVATS + ligation of intercostal } \\
\text { artery }\end{array}$ \\
\hline 14 & $\begin{array}{l}\text { in-vehicle traffic } \\
\text { accident }\end{array}$ & $\begin{array}{l}\text { Left hemopneumothorax } \\
\text { and multiple costal } \\
\text { fractures with tissue loss }\end{array}$ & Open wound at chest wall & $\begin{array}{l}\mathrm{RT}+\text { repair of parenchyma } \\
+ \text { fixation of ribs + chest wall } \\
\text { reonstruction }\end{array}$ \\
\hline 15 & $\begin{array}{l}\text { Stab and impalement } \\
\text { wounds }\end{array}$ & no & continuing drainage & $\begin{array}{l}\text { LVATS + ligation of intercostal } \\
\text { artery }\end{array}$ \\
\hline 16 & Gunshot injury & Left hemothorax & continuing drainage & $S+$ repair of parenchyma \\
\hline 17 & Acts of violence & $\begin{array}{l}\text { Left } \\
\text { hemopneumothorax }\end{array}$ & continuing drainage & $\begin{array}{l}\text { LVATS + ligation of intercostal } \\
\text { artery }\end{array}$ \\
\hline 18 & $\begin{array}{l}\text { Out-vehicle traffic } \\
\text { accident }\end{array}$ & no & Open wound at chest wall & $\begin{array}{l}\text { LAT + ligation of intercostal } \\
\text { artery + repair of parenchyma }+ \\
\text { chest wall reonstruction }\end{array}$ \\
\hline
\end{tabular}

LAT Left anterior thoracotomy, S Sternotomy, LT Left thoracotomy, RT Right thoracotomy, LVATS Left videothoracoscopic surgery, RVATS Right videothoracoscopic surgery 
The length of stay in the hospital was analyzed as the length of stay in the intensive care unit, and the total length of stay in the hospital. The length of stay in the intensive care unit ranged between 0 and 15 days (mean 4.4 days), and the total length of stay in the hospital was observed to be between 0 and 27 days (mean 12.3). The patient, who underwent pneumonectomy and left anterior thoracotomy due to traumatic asphyxia, was observed to be hospitalized in the intensive care unit during the entire stay, for a period of 15 days. All patients had low hemoglobin and low Glasgow coma scores; and all were performed surgery without performing tube thoracostomy. In our study, pneumonectomy was performed in 1 patient, while non-resection surgical procedures were performed in the other patients. This patient was administered a dialysis program 2 days a week due to chronic kidney disease. The frequency of dialysis was increased to 3 days a week after trauma. The patient died in the intensive care unit due to sepsis and multiple organ dysfunction. The patients who died had traumatic asphyxia, cardiac injury and superior vein injury. Active bleeding and hemopneumothorax were the predominant intraoperative findings in others.

While 16 of the patients, who underwent early surgery due to trauma, were discharged with full recovery, 2 of them died. The patients who died had traumatic asphyxia, cardiac injury and superior vein injury.

A total of 9 patients had cardiovascular injuries. In patients with cardiovascular injury, the mortality rate was found as $11.11 \%$. When the results of the treatment and the Glasgow coma scores were compared, it was observed that the mean Glasgow score was 12.2 in 16 patients, who were discharged with full recovery; and the mean Glasgow score was 6.2 in 2 patients who died. According to the evaluations, the Glasgow score was higher in the group of patients, who were discharged with full recovery compared to the other groups; and the difference was statistically significant $(\mathrm{p}=0.045)$. Cases; age, glasgow score and length of hospital stay were classified in table 2.

Table 2. Classification in age, glasgow score, and length of hospital stay.

\begin{tabular}{|c|c|c|c|c|c|}
\hline $\begin{array}{l}\text { Patient } \\
\text { Number }\end{array}$ & Age & Age Percent (\%) & Galsgow Score & $\begin{array}{c}\text { Total } \\
\text { hospitalization days }\end{array}$ & $\begin{array}{c}\text { Intensive care } \\
\text { hospitalization days }\end{array}$ \\
\hline 1 & 15 & 5,6 & 14 & 7 & 2 \\
\hline 2 & 16 & 5,6 & 9 & 11 & 4 \\
\hline 3 & 17 & 11,1 & 14 & 14 & 2 \\
\hline 4 & 19 & 5,6 & 4 & 10 & 5 \\
\hline 5 & 20 & 5,6 & 15 & 13 & 2 \\
\hline 6 & 21 & 5,6 & 15 & 8 & 2 \\
\hline 7 & 23 & 5,6 & 12 & 27 & 12 \\
\hline 8 & 24 & 11,1 & 14 & 12 & 7 \\
\hline 9 & 27 & 11,1 & 12 & 14 & 5 \\
\hline 10 & 29 & 5,6 & 7 & 15 & 15 \\
\hline 11 & 31 & 11,1 & 15 & 10 & 2 \\
\hline 12 & 36 & 5,6 & 15 & 11 & 2 \\
\hline 13 & 49 & 5,6 & 8 & 9 & 2 \\
\hline 14 & 57 & 5,6 & 10 & 13 & 3 \\
\hline 15 & 15 & 5,6 & 5 & 0 & 0 \\
\hline 16 & 16 & 5,6 & 9 & 17 & 4 \\
\hline 17 & 17 & 11,1 & 15 & 12 & 5 \\
\hline 18 & 19 & 5,6 & 14 & 19 & 5 \\
\hline Average & 26,8 & & 11,5 & 12,3 & 4,4 \\
\hline
\end{tabular}


The comparison between intubation and the results of the treatment revealed that 2 patients that were intubated died; and the patients, who were not intubated, survived. It was statistically significant that intubation was a poor prognostic factor $(p=0.035)$. Indications of emergency surgery and the results of the treatment were evaluated. It was found that hypovolemic shock was the surgical indication of the two cases who died. No statistically significant relationship was found between the results of the treatment and indications of emergency surgery $(\mathrm{p}=0.287)$.

Since parenchymal damage was observed in 3 patients who underwent emergency thoracotomy for bleeding, wedge resection was performed in 2 patients and pneumonectomy was performed in 1 patient.

When the correlation between the hemoglobin value and the length of stay in the intensive care unit was evaluated, a negative correlation was found between the two variables. This correlation was not found to be statistically significant (Kendall's tau-b, $p=0.456$, Spearman's rho, $\mathrm{p}=0.481$ ). Based on the results of the optimal scaling, it was determined that the results of the treatment were good in the patients with high Glasgow coma scores, who were performed emergency intervention in the emergency department, and who were not intubated.

Mortality analysis was performed using the Revised Trauma Score. The scoring was made according to the Glasgow Coma Score, arterial blood pressure and the respiratory rates. Among the patients with trauma scores between 3 and 12 (mean 8.5), the scores of the two patients who died were found as 4 .

\section{DISCUSSION}

Adebonojo et al. (8) mentioned that $10 \%$ of the patients with thoracic trauma evaluated by the emergency and ambulance medical teams died at the time of the event, 5\% died within the first hour after presenting to the hospital. In addition, they stated that $80 \%$ of the victims responded only to resuscitative treatment and tube thoracostomy, while the remaining 5\% required thoracotomy at the emergency department due to various reasons. Similarly, Wall et al. (9) reported that most patients with thoracic trauma can be treated by tube thoracostomy or by follow-up without surgery. They further mentioned that sufficient treatment results were obtained in $90 \%$ of the patients with careful monitoring of vital signs, appropriate fluid therapy and analgesia; however, emergency thoracotomy was still required in $10-15 \%$ of the patients with trauma (9). In our study, only $18(0.31 \%)$ of the 5784 cases, who were transferred to the emergency department and evaluated by the department of thoracic surgery, were performed emergency surgery. It was determined that the rate of emergency surgery was not as high as mentioned in the literature.

According to the previous studies, the risk of thoracic injuries and death due to trauma was higher in the males compared to the females; nonetheless, gender was not reported as an important variable in terms of mortality (10). In our study, all patients, who underwent emergency surgery, were male; therefore, no comparison was made on the gender.

In patients with thoracic trauma, the initial objective is to identify the injury as soon as possible; however, the first intervention is usually the tube thoracostomy (11-13). While 11 of the cases underwent tube thoracostomy as the first intervention in the emergency department before the surgery, 7 cases were performed surgery without tube thoracostomy. Thorax-CT could not be performed in 6 of these 7 cases due to their emergency. Although most penetrating thoracic injuries could be treated with simple surgical procedures, $10-15 \%$ of patients presenting with thoracic trauma require surgical repair $(14,15)$. In our study, it was observed that the majority of the patients, who were performed surgery, included the cases of hypovolemic shock, massive drainage and vascular injury. If the patient has cardiovascular injury, hypotension, clinical picture of shock, a hemorrhagic drainage of 1500 cc during tube thoracostomy or approximately 200 cc of drainage in every 1 hour, the patient should be operated immediately (16). There was massive drainage (800-1600 cc (mean $1200 \mathrm{cc}))$ in $10(55.6 \%)$ of our patients, $5(27.8 \%)$ of them had hypovolemic shock, $2(11.1 \%)$ of them had open thoracic injury, and $1(5.6 \%)$ of them had cardiac arrest. While 13 patients $(72.2 \%)$ had hypotension, 5 (21.8) patients were normotensive. Hemoglobin value was below 10 in 9 patients. While the lowest hemoglobin value was $4.8 \mathrm{~g} / \mathrm{dl}$, the mean HGB value was $9.9 \mathrm{~g} / \mathrm{dl}$. It was observed that low hemoglobin level correlated with low Glasgow Coma Value. Imaging could not be performed in patients, who were intubated in the emergency department. All patients had low hemoglobin and low Glasgow coma scores; and all were performed 
surgery without performing tube thoracostomy. Mortality increases in proportion to the size of the resection resulting from the parenchymal injury of the lung (16). In our study, pneumonectomy was performed in 1 patient, while nonresection surgical procedures were performed in the other patients. The patient, who underwent pneumonectomy, died in the intensive care unit in the early period due to sepsis and multiple organ failure.

Many surgical approaches have been described in the literature for the repair of the lung parenchyma. The parenchymal injury to the lung, and the resection performed due to the parenchymal injury to the lung was not found to have an effect on survival in some studies. However, in our study it was found that the parenchymal injury and the size of the resection had a negative effect on survival $(16,17)$

While median sternotomy is preferred when the cardiovascular injury is predominant in the patient evaluated in the emergency department, thoracotomy and video-assisted thoracic surgery (VATS) are highly preferred in patients with trauma (17). Similarly, in our study, the first choice was surgical incision sternotomy for injuries to the cardiac and the large vessel, and thoracotomy was the first choice for the injuries to the lung and the small vessel.

In our study, the mean length of stay in the hospital was 12.3 days. When compared with the literature, the length of stay in the hospital was similar. The mean length of hospital stay was 10.65 (range, 5-65) days (16).

Various mortality rates have been reported due to thoracic trauma in the literature. This could stem from the variety of the type of trauma. Mortality rates due to blunt and penetrating trauma have been evaluated both separately and together. However, the fact that patients have other systemic injuries diversifies the mortality rates. Zakharia (18) reported $1.7 \%$ mortality rate for the patients except for the patients with large vessel injuries. Onat et al. (16) reported $1.2 \%$ mortality rate for the patients with noncardiac injury and $17.6 \%$ mortality rate for the patients with cardiac injury. Degiannis et al. (19) mentioned 30.8\% mortality rate for the patients with cardiac injury; and Karmy-Jones et al. (20) reported $17 \%$ mortality rate for an emergency thoracotomy due to bleeding after penetrating chest trauma. Asensio et al. (21) reported a mortality rate of $59 \%$, and Hirshberg et al. (22) stated a mortality rate of $41 \%$ for 82 patients requiring combined laparotomy and thoracotomy. In our study, a total of 9 patients had cardiovascular injuries. In patients with cardiovascular injury, the mortality rate was found as $11.11 \%$ in our study, which was a similar rate compared to the literature. The mortality rate in the group of patients with no cardiovascular injury and the total mortality rate of both groups was again $11.11 \%$. This value was approximately similar to the literature.

The Revised Trauma Score is one of the most common physiological scoring methods recently. The trauma score of our patients who died was determined as 4 . The overall mean was calculated as 8.5. With the help of our improving healthcare system, emergency health services and the ambulance infrastructure, we believe that the continuation of treatment in competent centers after immediate and rapid intervention decreases the mortality rates of the patients, despite it is below 11 .

In conclusion, tube thoracostomy is sufficient for most of the patients with thoracic trauma. Nonetheless, surgery should be considered immediately in cases with a drainage of $1000-1500 \mathrm{ml}$ when the thoracic tube is first inserted, in cases with a drainage of $200-250 \mathrm{ml} /$ hour in the 3-hour follow-up. Deterioration of the hemodynamic state, massive hemothorax causing shock, symptoms of pericardial tamponade, massive air leak or radiographic evidence are all indications for emergency surgery.

\section{Declarations}

Financial Declaration: No financial or personal support was received from any company with a direct interest in the topic, that could influence the interpretation of the data and the results of the study.

Conflict of Interest: The authors have no conflicts of interest to declare.

Ethical statement: Ankara City Hospital Ethics Committee of the Ministry of Health Provincial Health Directorate on 25/06/2020 (No: E1-20-825) 


\section{REFERENCES}

1. Eray O. Approach to Multiple Trauma Patient (Golden Hour). Dogan R, Tastepe I, Liman ST (editors). Trauma. 1th, Ankara: MN Medikal \& Nobel; 2006: pp.93-103.

2. Çakan A, Yuncu G, Olgaç G, Alar T, Sevinc S, et al. Thoracic trauma: analysis of 987 cases. Ulus Travma Derg. 2001; 7(4): 236-241.

3. Kahraman $\mathrm{C}$, Akçal $\mathrm{Y}$, Emirogulları $\mathrm{N}$ et al. Künt toraks travması. Erciyes Tıp Dergisi. 1995; 17: 318-324.

4. Kish G, Kozloff L, Joseph WL, Adkins PC. Indications for early thoracotomy in the management of chest trauma. Ann Thorac Surg 1976;22(1):23-8

5. Hines $\mathrm{MH}$, Meredith JW. Special problems of thoracic trauma. In: Ritchie WP, Steele Jr G, Dean RH (editors). General surgery. Philadelphia: JB Lippincott; 1995. pp. 859-72

6. Onat S, Ulku R, Avci A, Ates G, Ozcelik C. Urgent thoracotomy for penetrating chest trauma: analysis of 158 patients of a single center. Injury 2011;42(9):900-4.

7. Champion HR, Sacco WJ, Copes WS, Gann DS, Gennarelli TA, Flanagan ME. A revision of the Trauma Score. J Trauma 1989; 29(5): 623-9.

8. Adebonojo SA. Management of chest trauma: a review. West Afr J Med 1993;12(2):122-32.

9. Wall Jr MJ, Storey JH, Mattox KL. Indications for thoracotomy. In: Mattox KL, Feliciano DV, Moore EE (editors). Trauma. 4th ed. New York: McGraw-Hill; 2000. pp. 473

10. Ali N, Gali BM. Pattern and management of chest injuries in Maiduguri, Nigeria. Ann Afr Med 2004;3(4):181-4.

11. Siemens R, Polk HC, Gray LA, Fulton RL. Indications for thoracotomy following penetrating thoracic injury. J Trauma 1977(7);17: 493-500.

12. Oparah S, Mandal A. Operative management of penetrating wounds of the chest in civilian practice. J Thorac Cardiouasc Surg 1979;77(2):162-8

13. Hines $\mathrm{MH}$, Meredith JW. Special problems of thoracic trauma. In: Ritchie WP,Steele Jr G, Dean RH (editors). General surgery. Philadelphia: JB Lippincott; 1995.pp. 859-72.

14. Thompson DA, Rowlands BJ, Walker WE, Kuykendall RC, Miller PW, et al. Urgent thoracotomy for pulmonary or tracheobronchial injury. J Trauma 1988;28(3):276-80.

15. Karmy-Jones R, Nathens A, Jurkovich GJ, Shatz DV, Brundage S, Wall MJ Jr, et al. Urgent and emergent thoracotomy for penetrating chest trauma. J Trauma 2004;56(3):664-668.

16. Zakharia AT. Cardiovascular and thoracic battle in the Lebanon war: Analysis of 3,000 personal cases. J Thorac Cardiovasc Surg 1985;89(5):723-733.

17. Degiannis E, Loogna P, Doll D, Bonanno F, Bowley DM, Smith MD. Penetrating cardiac injuries: recent experience in south africa. World J Surg 2006;30:1258-64.

18. Karmy-Jones R, Jurkovich GJ, Nathens AB, Shatz DV, Brundage S, Wall MJ Jr, et al. Timing of urgent thoracotomy for hemorrhage after trauma: a multicenter study. Arch Surg 2001;136(5):513-8.

19. Asensio JA, Arroyo Jr H, Veloz W, Forno W, Gambaro E, Roldan GA, et al. Penetrating thoracoabdominal injuries:ongoing dilemma-which cavity and when? World J Surg 2002;26(5):539-43.

20. Hirshberg A, Wall Jr MJ, Allen MK, Mattox K. Double jeopardy: thoracoabdominal injuries requiring surgical intervention in both chest and abdomen. J Trauma 1995;39(2):225-231 